\title{
Principais riscos e fatores de risco ocupacionais associados aos bombeiros, eventuais doenças profissionais e medidas de proteção recomendadas
}

TIPO DE ARTIGO: Revisão Bibliográfica Integrativa AUTORES: Santos M.(1), Almeida A.(2)

\section{RESUMO \\ Introdução/ enquadramento/ objetivos}

Os bombeiros estão expostos a inúmeros fatores de risco ocupacionais, capazes de originar acidentes de trabalho ou doenças profissionais relevantes. Apesar disso, o seu acompanhamento por equipas de saúde ocupacional é ainda escasso ou, em muitos casos, inexistente. Torna-se assim pertinente produzir evidência que exponha as necessidades mais frequentes deste setor profissional.

\section{Metodologia}

Pergunta metodológica: Durante o exercício da profissão de bombeiro, quais são os principais riscos/ fatores de risco ocupacionais, eventuais doenças profissionais e medidas de proteção recomendadas?

Foi realizada uma pesquisa bibliográfica em agosto de 2015 nas bases de dados "CINALH plus with full text, Medline with full text, Database of Abstracts of Reviews of Effects, Cochrane Central Register of Controlled Trials, Cochrane Database of Systematic Reviews, Cochrane Methodology Register, Nursing and Allied Health Collection: comprehensive, MedicLatina e Academic Search Complete", utilizando a palavra-chave "firefighter".

\section{Conteúdo}

Os bombeiros estão sujeitos a inúmeros riscos/ fatores de risco laborais, destacando-se o desconforto térmico, ruído, agentes biológicos, agentes químicos, esforço físico/ manuseamento de cargas, potencial oncológico, turnos prolongados e/ou noturnos (por vezes rotativos), stress/ burnout, cronodisrrupção e o próprio risco dos diversos acidentes possíveis.

As principais doenças profissionais mencionadas são a hipoacusia, o contágio com HIV, Hepatite B e/ou tuberculose, as doenças pulmonares crónicas obstrutivas (bronquite e enfizema), asma, rinossinusite, patologia oncológica variada, bem como ansiedade/ stress/ burnout/ cronodisrrupção.

Os artigos consultados são omissos face a medidas de proteção coletiva. Os EPls que a generalidade dos bombeiros usa são o fato (casaco e calça), capacete, cógula, luvas, óculos, bota de biqueira de aço e equipamento de proteção respiratória;

\section{Conclusões}

Apesar de existirem vários estudos que retratam a realidade portuguesa, a generalidade destes foca-se geralmente num 
aspeto em particular, não proporcionando uma visão global do setor. O estudo evidenciou que, em algumas situações, a segurança e saúde dos profissionais fica comprometida por diversos fatores interligados, de carater organizacional, condições de trabalho e crenças dos profissionais. Será desejável permitir o acesso a um serviço bem estruturado de Saúde Ocupacional, até porque uma parte significativa destes profissionais não é seguido neste contexto e os riscos/ fatores de risco são muito significativos.

PALAVRAS/ EXPRESSÕES-CHAVE: bombeiros, polícia e bombeiros em desastres, saúde ocupacional, saúde do trabalhador e medicina do trabalho.

\section{INTRODUÇÃO/ENQUADRAMENTO/OBJETIVOS}

Os bombeiros estão expostos a inúmeros fatores de risco ocupacionais capazes de originar acidentes de trabalho ou doenças profissionais relevantes. Apesar disso, o seu acompanhamento por equipas de saúde ocupacional é ainda escasso ou, em muitos casos, inexistente. Considera-se, por isso, importante, produzir evidência que exponha as necessidades em saúde ocupacional destes trabalhadores.

\section{METODOLOGIA}

Pergunta metodológica: Durante o exercício da profissão de bombeiro, quais são os principais riscos/ fatores de risco ocupacionais, eventuais doenças profissionais e medidas de proteção recomendadas?

Em função da Metodologia PICo foram considerados:

-P (population): bombeiros

-I (interest): produzir evidência sobre os principais riscos e fatores de risco existentes, eventuais doenças profissionais associadas e medidas de proteção recomendadas

-C (context): saúde ocupacional dos bombeiros

Foi realizada uma pesquisa bibliográfica integrativa em agosto de 2015 nas bases de dados "CINALH plus with full text, Medline with full text, Database of Abstracts of Reviews of Effects, Cochrane Central Register of Controlled Trials, Cochrane Database of Systematic Reviews, Cochrane Methodology Register, Nursing and Allied Health Collection: comprehensive, MedicLatina e Academic Search Complete". Utilizando a palavra-chave "firefighter" obtiveram-se 172 trabalhos; conjugou-se essa palavra-chave com "occupational", tendo-se obtido 107 artigos, usando como critérios, publicação igual ou superior a 2005 e acesso a texto completo; em função da língua original (portuguesa, inglesa ou espanhola) e da pertinência para o objetivo da revisão, foram selecionados, através do título, 30 artigos; após a consulta do resumo manteve-se o interesse por 29 trabalhos, tendo sido eliminado apenas um documento após a leitura integral.

Contudo, como praticamente não se encontram estudos relativos à realidade portuguesa nestas bases de dados indexadas, os autores procuraram trabalhos inseridos na base RCAAP (Repositório Científico de Acesso Aberto em Portugal). Aqui, utilizando a palavra-chave "bombeiro" foram obtidos 195 trabalhos; após a leitura do título e resumo foram selecionados 16 documentos que, após a consulta na íntegra, ficaram reduzidos a 11.

O resumo da pesquisa pode ser consultado nos fluxogramas de $1^{\mathrm{a}}$ e $2^{\mathrm{a}}$ fases. A caraterização metodológica e resumo dos artigos selecionados estão inseridos no quadro 1.

\section{CONTEÚDO}

Os bombeiros estão sujeitos a inúmeros riscos/ fatores de risco laborais; destacam-se neste contexto o desconforto térmico, ruído, agentes biológicos, agentes químicos, esforço físico/ manuseamento de cargas, potencial oncológico, turnos prolongados e/ou noturnos (por vezes rotativos), stress/ burnout, cronodisrrupção e o risco de acidentes diversos.

\section{Desconforto térmico}

Stress térmico pode ser definido como a quantidade de calor que tem de ser dissipado ou produzido para manter o corpo em 
equilíbrio. A capacidade para trabalhar em ambientes muito quentes é genericamente inferior à existente para ambientes muito frios $^{(1)}$.

Além das temperaturas elevadas a nível ambiental, em algumas circunstâncias, os bombeiros podem ter que usar EPIs pesados, quentes e/ou oclusivos, que potenciarão o desconforto térmico e a desidratação(1-3). A principal defesa do organismo perante o calor é a transpiração. Contudo, a não ingestão de água e o uso EPIs oclusivos pode prejudicar tal processo. Junto com o aporte de água os bombeiros devem ingerir também carbohidratos e eletrólitos; deve ser evitado o consumo de cafeína e de álcool, dado estes potenciarem a desidratação. Devido às elevadas temperaturas provenientes da radiação térmica das chamas, os bombeiros necessitam de dissipar mais calor ${ }^{(1)}$. Nas pausas de 20 a 30 minutos os bombeiros devem por isso remover os EPIs e hidratar-se ${ }^{(3)}$.

Bombeiros com mais idade e/ou tempo de serviço apresentam menos alterações fisiológicas associadas ao desconforto térmico, eventualmente devido a uma melhor aclimatização(2); a tolerância ao calor será maior também em função da hidratação e da capacidade física. O excesso de peso, por sua vez, perturba a tolerância ao calor, sudação e frequência cardíaca, potenciando-se assim também os riscos cardiovasculares. De realçar que a aclimatização pode ser definida como o processo lento e progressivo de adaptação fisiológica, que aumenta a tolerância térmica do indivíduo; ou seja, a sudação inicia-se mais cedo e tem menor concentração salina, verificando-se também uma melhor distribuição sanguínea e menos alterações na frequência cardíaca(1).

A atividade física intensa associada a temperaturas elevadas pode aumentar a atividade inflamatória; tal irá aumentar a rigidez arterial, diminuir o volume de ejeção ventricular e potenciar a coagulação; por isso, alguns dos marcadores inflamatórios são preditores do risco cardiovascular. Para além disso, a repetição da exposição a temperaturas elevadas pode deprimir o sistema imune, pelo que as infeções e os processos oncológicos poderão também ficar mais prevalentes ${ }^{(4)}$.

A recuperação perante a exposição ao calor subdivide-se em passiva e ativa; a primeira consiste em retirar o bombeiro do combate às chamas, para um ambiente de cerca de $15^{\circ} \mathrm{C}$, com remoção dos EPIs e com acesso a água. Por sua vez, a recuperação ativa é baseada em sistemas de arrefecimento por convecção forçadas, sobretudo através da água ou gelo. Às vezes basta apenas que um ventilador potencie a circulação do $\operatorname{ar}^{(1,3)}$; contudo, para ser eficaz, a temperatura do ar deve ser inferior à cutânea; podem também ser utilizados ventiladores que fornecem uma nuvem de vapor de água (no entanto, o vestuário e os EPIs podem ficar humedecidos e perturbar posteriormente o equilíbrio térmico). A utilização de água entre 10 a $20^{\circ} \mathrm{C}$ é mais eficaz nos pés, mãos e antebraços ${ }^{(1)}$. No arrefecimento através do gelo, geralmente são utilizados coletes que podem conter blocos deste material, contudo, a estrutura torna-se volumosa e pesada ${ }^{(1,3)}$.

\section{Ruído}

A perda auditiva associada ao ruído ocorre com exposições prolongadas, gradualmente, danificando o ouvido interno; tal patologia não tem tratamento mas é prevenível através da diminuição do ruído, por exemplo, com técnicas de engenharia; contudo, estas, por vezes, são demasiado complexas e/ou dispendiosas para serem aplicáveis; pelo que, paralelamente, poderá ser utilizada a proteção auricular; contudo, o seu uso pelos bombeiros não é consistente, apesar de ser frequente a exposição superior a 85 dBAs. O preditor mais forte para o uso de proteção auricular é a influência interpessoal (colegas e chefia) $)^{(5)}$.

Alguns investigadores concluíram que a perda de audição nos bombeiros avaliados era superior à espetável para a idade ${ }^{(5,6)}$, sobretudo na fase inicial da carreira ${ }^{(6)}$. A perda de audição que ocorre nos bombeiros é neurossensorial ${ }^{(7)}$.

Um estudo norte-americano quantificou que 13 dos 15 equipamentos de trabalho utilizados num departamento de bombeiros emitiam som equivalente ou superior a $85 \mathrm{dBAs}$; o ruído mais intenso $(91 \mathrm{dBA})$ era proveniente dos motores para a bomba de água $^{(8)}$; outros artigos, por sua vez, afirmavam que o ruído mais intenso era proveniente da sirene do camião e de alguns alarmes do equipamento utilizado ${ }^{(5)}$.

Num estudo brasileiro concluiu-se que cerca de $27 \%$ da amostra estudada apresentava perda auditiva e, em $36 \%$ dos casos, esta era bilateral. Aqui foram também registados os decibéis em diversos locais/ equipamentos; por exemplo, no ambiente exterior quantificaram-se $79 \mathrm{dbA}$; nos "head-sets" 92, na moto operacional 92, no camião com sirene desligada 81 e ligada 100, na bomba de água 100, na motosserra média 106 e na pequena $98 \mathrm{dbA}$. As queixas mais frequentes neste contexto eram o desconforto, acufeno e a disacusia. A maioria dos avaliados não usava proteção auricular e uma minoria apenas o fazia 
esporadicamente $^{(7)}$.

Ainda assim, alguns autores realçam que parte do ruído inerente à atividade de bombeiro é menos contínuo que na generalidade do setor industrial; contudo, simultaneamente, o tempo de repouso poderá, ainda assim, não permitir que as células acústicas recuperem ${ }^{(9)}$.

Apesar de não vir diretamente mencionado na bibliografia selecionada, os autores querem destacar que nos últimos anos têm sido publicadas investigações que sugerem a possibilidade do ruído também se associar a várias alterações cardiovasculares (hipertensão arterial, taquicardia- aumento da frequência cardíaca e isquemia do miocárdio), alterações do sono, respiratórias, obstétricas, imunológicas; bem como consequências a nível de desempenho e em variáveis psicológicas el ou neuropsiquiátricas.

\section{Cronodisrrupção}

Outra situação pouco destacada nos artigos selecionados foi a da cronodisrrupção; ainda assim, há que salientar que está descrita com clareza a contribuição dos turnos noturnos, sendo que a rotatividade de horários poderá potenciar ainda mais o problema. O desempenho laboral é menor na fase em que a temperatura corporal está no valor mais inferior, ou seja, entre as quatro e as seis horas da manhã. Na primeira noite de trabalho geralmente não se verifica diminuição considerável do desempenho mas, nas noites seguintes, surgem atraso de raciocínio, tempos de reação maiores, mais erros e pior memória. $\mathrm{O}$ maior risco de acidentes laborais em todos os estudos consultados, de todas as áreas, situa-se durante a noite e/ ou madrugada. O risco é também superior nos turnos mais prolongados; sendo que as pausas/ sestas estão em situação oposta. Alguns estudos defendem que a mortalidade dos trabalhadores por turnos noturnos (presentemente ou no passado apenas) é superior à dos trabalhadores que só fazem ou fizeram turnos diurnos e regulares. Um sono adequado associa-se a melhor qualidade de vida, memória e humor, bem como sistema imune mais fortalecido, melhor nível de alerta e de reatividade. Durante a noite a secreção de cortisol e adrenalina é baixa, acontecendo o oposto durante o dia; assim, os trabalhadores noturnos que tentam dormir durante o dia, devido também a estas duas hormonas, terão um sono mais curto e menos reparador e, durante a noite, terão pior desempenho laboral. A Agência Internacional de Pesquisa para o Cancro (IARC) classificou o trabalho por turnos noturnos como "provavelmente carcinogénico", desde 2007, em função do desequilíbrio circadiano.

\section{Agentes biológicos}

As patologias associadas aos principais agentes biológicos neste contexto profissional são as hepatites $\mathrm{B}$ e $\mathrm{C}$, bem como a $\operatorname{SIDA}(10,11)$; sobretudo em relação ao socorro prestado a vítimas de acidentes e ao transporte de doentes. Nos casos adequados, poderá ser pertinente proporcionar imunização para a hepatite $\mathrm{B}^{(10)}$.

Aliás, no contexto dos sinistros é mais difícil o uso correto dos EPIs. Para além disso, nos procedimentos de desinfeção dos utensílios, por vezes, parte dos bombeiros não usa qualquer EPI por achar que não existe risco. O rigor no uso dos mesmos também pode ficar prejudicado com o cansaço proveniente dos turnos prolongados e/ou pela cronodisrrupção secundária aos turnos noturnos e/ou rotativos ${ }^{(10)}$. Por vezes os bombeiros tentam fazer suporte básico de vida e/ou têm que manusear agulhas usadas, dentro de uma ambulância em movimento, em espaços confinados e/ou com pouca visibilidade. Para além disso, os sinistrados podem estar recobertos por vidro, o que aumenta mais o risco, além de poderem existir grandes hemorragias e/ou estarem desorientados, agitados e/ou agressivos. No local do acidente podem nem ter acesso a um recipiente adequado para depositar agulhas e outros objetos cortantes e/ou simplesmente lavar as mãos, como acontece com os profissionais de saúde, dentro das instituições ${ }^{(11)}$.

Um estudo quantificou que cerca de $8 \%$ das infeções ocupacionais por HIV atingia os bombeiros. Quanto à tuberculose, e no contexto dos EUA, também esta foi razoavelmente prevalente nesta classe, a nível de infeções ocupacionais ${ }^{(12)}$.

\section{Riscos respiratórios}

Muito frequentemente os bombeiros têm de trabalhar sob condições adversas a nível de poeiras e concentração de oxigénio(4).

Em alguns países os profissionais que atuam em incêndios na natureza são distintos dos que trabalham em zonas urbanas; 
sendo que os últimos mais frequentemente usam equipamentos de proteção respiratória(13, 14$)$.

Os fogos florestais produzem mais partículas inaláveis (menores que 100 micrómetros), contendo derivados do carbono (13-16) (como o monóxido) $(13,14,16)$ e seus percursores, capazes de reagir com o peróxido de oxigénio, formando o radical hidroxilo $(13,14)$, induzindo processos inflamatórios $(14,17)$. Tal contribui para a diminuição da função pulmonar e respetiva semiologia $(14,18,19)$. Está também descrita neste contexto a exposição a hidrocarbonetos e óxidos de nitrogénio ${ }^{(18)}$; bem como a acroleína, formaldeído e o benzeno ${ }^{(21)}$. A inalação aguda ao fumo induz aumento da inflamação sistémica, mesmo na ausência de hiperresponsividade brônquica $(20,21)$ (sendo esta, ainda assim, mais frequente nos atópicos) ${ }^{(19)}$. A exposição cumulativa pode implicar diminuição discreta da função pulmonar $(16,21)$. Mesmo quando os bombeiros têm equipamento de proteção respiratória disponível, por vezes, este não é utilizado, devido à sensação subjetiva da quantidade de fumo ser escassa $(19,20)$. A exposição ao fumo é também proveniente dos contrafogos (18) ou dos fogos preventivos realizados antes da época mais quente, altura em que a vegetação está mais desenvolvida e se produz maior quantidade de fumo(16). Além da generalidade dos turnos ser prolongada (12 a 18 horas), não é viável o uso contínuo de um aparelho respiratório e já há geralmente um grande esforço físico, que implica um aumento do volume corrente respiratório. Por vezes, o próprio sítio onde repousam não é isento de riscos pulmonares ${ }^{(21)}$.

Vários estudos revelaram que alguns bombeiros de Nova lorque, expostos às poeiras e produtos secundários à combustão ${ }^{13,22)}$, resultantes da queda das torres gémeas, apresentavam diminuição da função pulmonar- nos primeiros seis meses mais de metade dos indivíduos estava nessa condição ${ }^{22,23)}$. Observou-se ainda que a incidência de asma, bronquite e enfizema ficou aumentada ${ }^{(23)}$, bem como da rinossinusite crónica. Foi também relevante neste contexto a exposição a metais, radionucleótidos, asbestos, hidrocarbonetos aromáticos policíclicos, bifenilos e dibenzodioxinas ${ }^{(24)}$.

\section{Riscos cardíacos}

Esta classe profissional apresenta uma incidência de eventos cardiovasculares e respetiva mortalidade superiores à população geral. Alguns investigadores relacionam tal facto com a exposição ao fumo dos incêndios (para além do esforço físico, EPls pesados, desconforto térmico, trabalho por turnos, stress e fatores de risco cardiovascular pessoais)-( 21 ) ou seja, $40 \%$ destes profissionais têm excesso de peso ou obesidade ${ }^{(4,25)}$; o tabagismo é também muito prevalente ${ }^{(25)}$. A principal causa de mortalidade é a morte súbita $\left(50 \%\right.$ das mortes em serviço, no combate a incêndios) ${ }^{(4,13,21,25)}$. A atividade física intensa sobreposta às temperaturas elevadas, desidratação, trombocitose e stress, pode justificar o aumento da incidência de paragens cardíacas/ mortes súbitas $(4,13,25)$; estando também descritos casos de acidente vascular cerebral e embolia pulmonar $^{(4)}$. Alguns investigadores também defendem que a exposição por inalação a partículas resultantes dos incêndios aumenta a rigidez arterial e, consequentemente, a probabilidade de surgir aterosclerose e/ou hipertensão arterial ${ }^{(13)}$. Um estudo espanhol comparou o esforço executado no combate aos incêndios florestais, em média, como sendo equivalente a correr com cerca de 20 quilogramas extra e com uma temperatura média de $39^{\circ} \mathrm{C}^{(26)}$.

\section{Risco oncológico}

Apesar de alguns estudos reportarem relações estatisticamente significativas entre o trabalho de bombeiro e patologia oncológica(26-29)_ como mieloma múltiplo(30), linfoma não Hodgkin ${ }^{(22)}$, cancro cerebral, do sistema digestivo, aparelho genitourinário $^{(31)}$, cancro da próstata $(21,27,28)$, pulmão $(27,28)$ e do testículo(21), a IARC (Agência Internacional para a Investigação sobre o Cancro) considerou que a evidência era limitada, pelo que classificou esta exposição ocupacional como possivelmente carcinogénica para humanos (categoria 2b) (21,27-29). Contudo, o benzeno, o formaldeído e a acroleína são carcinogénicos $(21,27,28)$. Ainda neste contexto há a considerar a cronodisrrupção associada aos turnos noturnos e/ou rotativos.

\section{Stress}

O facto dos bombeiros enfrentarem com alguma frequência situações onde a vida humana é ameaçada (a sua e/ou dos outros) ou até interrompida, tal poderá contribuir para a existência de stress pós-traumático $(30,31)$ e/ou dissociação. Esta última carateriza-se pela ocorrência de um distanciamento emocional, que permite que o indivíduo viva a situação não como participante, mas mero espetador. Estudos internacionais quantificam a prevalência de stress pós-traumático na ordem dos $25 \%$; dois estudos nacionais obtiveram percentagens de 3,9 e 7,4\%. Alguns investigadores defendem que a maior quantidade de eventos traumáticos potencia a existência deste diagnóstico, sendo a dissociação altamente preditora do mesmo ${ }^{(30)}$. 0 
stress associa-se também à complexidade e dificuldade na tomada de decisões e à existência de conflitos com doentes, familiares, colegas e/ou chefia ${ }^{(10)}$. Nas profissões onde o trabalhador é obrigado a lidar com o sofrimento e necessidades do outro, as relações interpessoais podem tornar-se stressantes, contribuindo para a sua exaustão emocional; o distanciamento eventualmente criado para defesa pode, contudo, tornar-se disfuncional ${ }^{(32)}$. Coping, por sua vez, poderá ser definido como o conjunto de dimensões cognitivas ou estratégias que um indivíduo pode utilizar para lidar com o stress(33).

Outros autores afirmam que o stress ocupacional será mais frequente nos contextos profissionais onde predomine uma maior exigência e um menor controlo. Ele pode mais facilmente surgir quando o indivíduo considera que está a executar atividades fora das suas funções, tarefas que não gosta, quando existe insatisfação com a remuneração, conflitos com chefias e/ou colegas, ambiguidade de papéis, progressão na carreira insuficiente ou inexistente, falta de segurança no vínculo laboral, não participação nas decisões, má integração na organização, desagrado pela liderança, sobrecarga de tarefas, ausência de reconhecimento, falta de justiça e conflitos éticos. O stress é, por sua vez, mitigado pela sensação de controlo, compromisso e desafio (ou seja, veem a mudança como algo aliciante em vez de ameaçador e trágico) ${ }^{(34)}$; bem como extroversão, bom autoconceito, otimismo e sentido de humor ${ }^{(33)}$.

A nível fisiológico o stress implica aumento na produção de aldosterona e cortisol, bem como adrenalina e noradrenalina; o que poderá trazer alterações no padrão de sono, tensão arterial, função imune e alterações no metabolismo das proteínas, glicose e lípidos ${ }^{(34)}$.

Neste contexto, como medidas de prevenção primária, pode ser destacada a existência de programas que permitam o desenvolvimento pessoal de estratégias para lidar com adversidade, durante e após o evento; para além de providenciar apoio psicológico adequado(30).

Alguns estudos norte-americanos quantificaram que cerca de um quarto dos bombeiros profissionais estudados tinha considerado, pelo menos uma vez, a ideia de suicídio; valor esse discretamente inferior nos voluntários $(18,4 \%)^{(35)}$.

Um estudo brasileiro quantificou a existência de stress como moderada na amostra estudada; sendo que os mecanismos de coping mais utilizados foram a aceitação da responsabilidade, reavaliação positiva, autocontrolo, uso do suporte social, fuga/afastamento ou confronto. Alguns autores também destacam medidas como a meditação, exercício e melhoria na comunicação(34).

\section{Burnout}

O stress ocupacional extremo e continuado pode originar situações de burnout, ou seja, pode ocorrer uma perda gradual de emoções, motivação e empenho; surgem também eventualmente a desilusão, irritação, frustração e depressão(26,32-34). 0 indivíduo sente-se esgotado/ desmotivado e não consegue relaxar. Por vezes, surgem também sintomas físicos ${ }^{(32-34)}$ (como cefaleia, mialgia, náusea, alterações do sono e astenia) ${ }^{(33,34)}$. O burnout também é mais frequente nos indivíduos com um nível educacional mais elevado(34), em profissões que prestam ajuda por contato direto(32), nos mais dedicados e empenhados, bem como nos mais idealistas e motivados( ${ }^{(34)}$. É também mais provável em situações de acidentes graves ou até morte de colegas, em consequência do exercício das suas atividades. ${ }^{26)}$. A nível de caraterísticas individuais que possam estar associadas a burnout destacam-se a experiência profissional e o estilo de coping. Quanto às caraterísticas do trabalho, são salientados o conflito de papéis, pressão, contato direto com o cliente e o incumprimento de expetativas. Por fim, em relação às condições organizacionais, podem ser mencionadas a falta de participação na tomada de decisão e a relação trabalhador/ cliente. Para a instituição o burnout pode acarretar maior absentismo, maior turnover de funcionários e pior desempenho( ${ }^{(32)}$.

\section{MEDIDAS DE PROTEÇÃO COLETIVA}

Entre os artigos selecionados, nenhum regista de forma direta medidas de proteção coletiva. Os autores podem, contudo, destacar a rotatividade de tarefas, a evicção de turnos prolongados sem pausas adequadas, acesso a nutrição e hidratação corretas durante essas pausas, uso de agentes químicos menos tóxicos (se aplicável), seleção de equipamentos menos ruidosos, aclimatização (se pertinente), acessos a sistemas de arrefecimento eficazes, diminuição da carga transportada durante o turno, vigilância médica e psicológica adequadas, cumprimento dos condicionamentos médicos e formação profissional. 
Os EPIs que a generalidade dos bombeiros usa são o fato (casaco e calça), capacete, cógula (máscara de tecido), luvas e bota de biqueira de aço. A roupa geralmente é constituída por três camadas que proporcionam as barreiras externa aos níveis de humidade e temperatura. Alguns investigadores defendem que o uso de t-shirt e calções por debaixo do fato não aumenta o risco de queimaduras e facilita o equilíbrio térmico(1).

O uso de alguns EPls implica um acréscimo de carga a transportar considerável, com destaque para o calçado, roupa e equipamentos de proteção respiratória; realçando-se o respetivo impacto a nível de gasto calórico e consumo de oxigénio. Um estudo quantificou que o uso dos EPIs avaliados induziu 56\% de decréscimo na tolerância ao exercício(29); o que também potencia ainda mais o desconforto térmico. Alguns autores quantificaram que estes podem adicionar cerca de $30 \mathrm{kgs}$ à carga que o bombeiro tem de mobilizar ${ }^{(1)}$.

\section{Acidentes}

A incidência de acidentes nos bombeiros é superior à que existe na generalidade das outras classes profissionais ${ }^{(36,37)}$ e aqui predominam os entorses ${ }^{(35,36)}$, LMEs, cortes ${ }^{(36,38)}$ e queimaduras ${ }^{(38)}$. Nos estudos consultados, um terço dos acidentes ocorreu em atividades de treino e mais de um quarto no combate a incêndios; $13 \%$ dos mesmos estiveram associados à mobilização e transporte de doentes ${ }^{(36)}$. A maioria das situações de emergência exige posturas forçadas e mantidas, daí o maior risco de acidente ${ }^{(37)}$. O cansaço secundário aos turnos prolongados e noturnos também pode contribuir para os acidentes de viação, além de que as viaturas em causa são complexas e de grande dimensão(26).

Alguns estudos descrevem uma variabilidade da sinistralidade dependente da hora do dia, ou seja, o risco de acidentes no turno noturno é superior e neste horário geralmente os eventos são mais graves; eventualmente devido a piores coordenação motora, atenção e cognição( ${ }^{(38)}$, como já se mencionou.

Num estudo norte-americano de 2012, onde se avaliou a sinistralidade neste setor, verificou-se uma diminuição dos acidentes ao longo das três últimas décadas, ou seja, passaram de 100.000 no início da década de oitenta para 69.400 em 2012 ; e, nesse ano, $45 \%$ deles estavam associados ao combate a incêndios. Globalmente, $55 \%$ referiam situações de entorse; $12 \%$ associavam-se a feridas/ cortes/ hematomas e $6 \%$ relacionavam-se com o stress térmico e queimaduras ${ }^{(26)}$.

\section{Realidade portuguesa}

A nível nacional, o enquadramento, missão e objetivos dos Bombeiros Municipais estão definidos pelo Decreto-lei 106/2002; a carreira de bombeiro, por sua vez, está registada no Despacho Conjunto 297/2006; outros decretos-lei com dados associados são o 241/2007 e 247/2007. A missão destes abarca o socorro em todos os acidentes e catástrofes, bem como prevenção contra incêndios; poderão também fornecer pareceres técnicos a nível de prevenção e segurança contra sinistros e riscos de incêndio $(26,39)$. No nosso país os bombeiros não se limitam a apagar fogos; também recebem solicitações em relação a busca, inspeção, salvamento e resgate; podem ter que lidar com agentes químicos perigosos e desconhecidos ou atuar perante atividades terroristas e acidentes (industriais, domésticos e a nível de transportes) ${ }^{(1,26)}$; bem como colaborar com a proteção civil e exercer atividade de formação cívica (sobretudo contra incêndios e acidentes) ${ }^{(26)}$.

A formação inicial prestada a estes profissionais é da responsabilidade da Escola Nacional de Bombeiros, Regime dos Sapadores/ Bombeiros e pelos Corpos de Bombeiros; aqui é dado particular destaque para a utilização e segurança perante o uso de EPIs, manuseamento de ferramentas e noções breves sobre o trabalho em equipa(26).

Quando questionados relativamente ao facto de sentirem desconforto térmico no exercício das suas funções, $82 \%$ afirmou sentir muito calor. Durante o combate aos incêndios, $98 \%$ afirmou ingerir líquidos; 42 e 39\% faziam-no nas quantidades de um a dois litros por hora, sensivelmente; $8 \%$ ingeria mais que dois litros. Quanto ao produto em si, $69 \%$ usava água e $9 \%$ leite. Em relação às técnicas de arrefecimento, apenas 33\% afirmou ter alguma informação; destes, 37\% mencionaram a ingestão de água, $24 \%$ referiram a imersão em água a $10^{\circ} \mathrm{C}$ e abrir/ despir o casaco(1).

No combate a fogos intensos, 15 a $22 \%$ dos bombeiros inquiridos era rendido apenas em 12 e $24 \mathrm{~h}$, respetivamente (contudo, $53 \%$ não respondeu a esta questão) ${ }^{(1)}$. Num estudo efetuado com os bombeiros de Viana do Castelo, constatou-se que o tempo de combate às chamas não é controlado, pelo que se encontraram situações em que os operacionais estiveram ao 
serviço 50 horas consecutivas; aliás estes profissionais consideravam que o seu maior problema ocupacional era justamente a ausência de pausas adequadas nas ocorrências prolongadas, quase sem oportunidade para comer, beber ou descansar. Os manuais da Escola Nacional de Bombeiros incentivam que os operacionais devem descansar por turnos, em grupo e numa área já ardida; como se, nestas condições, fosse possível um descanso adequado e como não fossem inaladas substâncias nocivas. Um estudo orientado pela universidade de Aveiro concluiu que algumas partículas emitidas nos incêndios são muito nocivas, nomeadamente hidrocarbonetos aromáticos policíclicos (com elevado potencial oncológico); além do monóxido de carbono (que pode ser fatal acima de determinada concentração) ${ }^{(26)}$.

Num estudo nacional concluiu-se que cerca de $12 \%$ dos bombeiros avaliados apresentavam um padrão espirométrico obstrutivo (ainda que $43 \%$ destes também fossem tabagistas)(21). Noutro estudo, $44 \%$ dos entrevistados afirmou ter semiologia ou patologia respiratória; os sintomas mais frequentemente mencionados foram a tosse com ou sem expetoração $(23 \%)$, pieira $(10 \%)$, toracalgia (4\%); as doenças mais frequentemente descritas foram a asma (4\%), bronquite ou enfizema (3\%). Após realização das provas de função respiratória $17 \%$ destas apresentavam alterações obstrutivas. Os investigadores concluíram que existia uma relação estatisticamente significativa entre as alterações obstrutivas e o número de anos como bombeiro(17).

Relativamente ao stress ocupacional, um estudo nacional concluiu que este está associado à inadaptação para as tarefas, falta de controlo sobre as mesmas, falta de apoio, insegurança quanto ao atingimento dos objetivos pretendidos/ desejados, não saber quando irão ser chamados a atuar e em quê, falta de recursos humanos para dividir as tarefas, tarefas simultâneas, situação grave das vítimas (encarceradas ou presas no fogo), sinistrados infantis, má comunicação/ coordenação, ter de dar a notícia de falecimento aos familiares, maus tratos proporcionados pelos doentes/ sinistrados e/ou seus familiares e até pelos comentários da população ao desempenho global da equipa ${ }^{(1)}$.

Alguns entrevistados afirmaram que o seu ambiente familiar era influenciado pelo stress ocupacional; outros evitavam dar detalhes em casa acerca do trabalho, para não preocupar os familiares. Quando questionados sobre o que poderia atenuar o stress, alguns mencionaram a existência de uma melhor organização e comunicação, bem como mais colegas para repartir tarefas e descansar mais. Ainda neste estudo, $52 \%$ dos bombeiros inquiridos considerou que a atividade era geradora de stress; sendo que nestes, $35 \%$ o associava à possibilidade de ocorrerem acidentes e $29 \%$ salientava os incêndios ${ }^{(1)}$.

Um estudo nacional quantificou que a dissociação pós-traumática na amostra estudada atingiu os $45,4 \%$; tal poderá ser preocupante na medida em que permite inferir que quase metade destes profissionais não possui outras estratégias adaptativas para lidar com a adversidade ${ }^{(30)}$.

Outro estudo nacional que incidiu sobre 302 bombeiros da zona centro do país, concluiu que existia associação entre alguns traços de personalidade e o stress; por exemplo, o neuroticismo apresenta correlação positiva e a extroversão correlação negativa, ou seja, maior neuroticismo potencia a perceção do stress, contribuindo também para uma maior ansiedade, menor capacidade para gerir impulsos, menor capacidade para relaxar, menor confiança e pior coping; a extroversão, por sua vez, contribui para uma maior intensidade e qualidade nas relações interpessoais. Para além disso, os bombeiros profissionais/ efetivos apresentam níveis de stress superiores aos voluntários; tal como indivíduos com menor número de anos de atividade (eventualmente por uma eventual aquisição de estratégias de coping ao longo do tempo) ${ }^{(33)}$.

Quanto à avaliação da condição física destes bombeiros, um dos trabalhos revelou que $36 \%$ era sedentário e $30 \%$ fazia apenas exercício físico uma vez por semana; entre os que praticavam, as sessões duravam entre 30 a 60 minutos, em $43 \%$ dos casos; ainda que $73 \%$ achasse que a forma física era importante para o desempenho laboral ${ }^{(1)}$.

No que diz respeito a acidentes laborais, $60 \%$ não tinha tido qualquer sinistro enquanto $32 \%$ registava um a três eventos. A maioria dos acidentes estava relacionada com entorses e queimaduras (80 e 13\% de primeiro e segundo grau, respetivamente) $)^{(1)}$. Noutro estudo nacional, $54 \%$ já tinha tido pelo menos um acidente; na maioria, apenas um evento. No momento dos acidentes, os sinistrados estavam em serviço, em média, 11 horas; a grande parte destes tinha ocorrido nos turnos da tarde e noite. Neste contexto, os traumatismos são quatro vezes mais frequentes que as queimaduras ${ }^{(26)}$.

Quanto aos EPIs utilizados, 19\% afirmou usar capacete, óculos e cógula; $12 \%$ também referiu utilizar botas e luvas; $90 \%$ acrescentou que os EPIs eram fornecidos pela corporação. Quanto à existência de EPI para o frio, $79 \%$ dos inquiridos afirmou possuir. Apesar de $71 \%$ considerar que o uso deste EPI dificultava a evaporação do suor, a maioria (52\%) referiu que este era fácil de vestir/ despir, $43 \%$ que era adequado ao seu trabalho (?) enquanto $42 \%$ qualificou-o como confortável(1). 
Contrariamente, noutro estudo nacional, $85 \%$ dos bombeiros afirmou não possuir qualquer EPI(26).

Relativamente ao uso concreto dos EPIs, um outro estudo português, que avaliou 357 bombeiros, concluiu que apenas $38 \%$ usava proteção respiratória durante o combate a incêndios, ainda que apenas $9,5 \%$ o fizesse sem exceções, ou seja, $6,7 \%$ dos que usavam faziam-no em menos que um quarto das vezes, $13 \%$ apenas em metade dos casos e $9 \%$ em $75 \%$ das situações $^{(17)}$.

No que diz respeito às condições de trabalho dos bombeiros portugueses, 43 e $41 \%$ consideravam que estas eram boas ou razoáveis, respetivamente; $90 \%$ achava que eram muito boas e apenas $3 \%$ as retratou como más (nenhum as quantificou como muito más). Neste mesmo estudo verificou-se que apenas $51 \%$ tinha tido exame médico de admissão. Quanto aos exames periódicos, $45 \%$ nunca os realizou, enquanto que $26 \%$ fazia-os anualmente (o autor não fez qualquer distinção entre idades). Quanto à existência de acompanhamento psicológico, apenas $21 \%$ referiu ter essa possibilidade (contudo, o autor destaca que, dentro da mesma corporação, as respostas foram contraditórias) $)^{(1)}$.

\section{CONCLUSÕES}

Apesar de existirem vários estudos que retratam a realidade portuguesa, a generalidade destes foca-se geralmente num aspeto em particular, não proporcionando uma visão global do setor. O estudo evidenciou que, em algumas situações, a segurança e saúde dos profissionais fica comprometida por diversos fatores interligados, de carater organizacional, condições de trabalho e crenças dos profissionais. Será desejável permitir o acesso a um serviço bem estruturado de Saúde Ocupacional, até porque uma parte significativa destes profissionais não é seguido neste contexto e os riscos/ fatores de risco são muito significativos.

\section{CONFLITOS DE INTERESSE, QUESTÕES ÉTICAS E/ OU LEGAIS}

Nada a declarar.

\section{AGRADECIMENTOS}

Nada a declarar.

\section{BIBLIOGRAFIA}

1)Quintal P. Caraterização do stress térmico no combate a incêndios e avaliação de sistemas de arrefecimento individual. Tese de Mestrado em Engenharia Mecânica, Especialidade de Engenharia e Ambiente, Faculdade de Ciências e Tecnologia da Universidade de Coimbra. 2012, 1-84.

2)Wright $\mathrm{H}$, Larose $J$, McLellan T, Miller $\mathrm{S}$, Boulay $\mathrm{P}$, Kenny $\mathrm{G}$. Do older firefighters show long term adaptations to work in the heat? Journal of Occupational and Environmental Hygiene. 2013, 10, 705- 715.

3)McEntire S, Suyama J, Hostler D. Mitigation and preventive of exertional heat stress in firefighters: a review of cooling strategies for structural firefighting and hazardous materials responders. Prehospital Emergency Care. 2013, 17(2), $241-260$.

4)Wright-Beatty H, McLellan T, Larose J, Sigal R, Boulay P, Kenny G. Inflammatory responses of older firefighters to intermittent exercise in the heat. European Journal of Applied Physiology. 2014, 114, 1163-1174.

5)Hong O, Chin D, Ronis D. Predictors of hearing protection behavior among firefighters in the United States. International Journal of Behavior Medicine. 2013, 20, 121- 130.

6)Ide C. Hearing losses in wholetime firefighters occurring early in their careers. Occupational Medicine. 2011, 61, 509-511.

7)Taxini C. Avaliação audiológica e quantificação da exposição ao ruído em profissionais do corpo de bombeiros. Tese de Mestrado, Faculdade de Filosofia e Ciências, Fonoaudiologia. 2013, 1- 67.

8)Root K, Schwennker C, Autenrieth D, Sandfort R, Lipsey T, Brazile W. Firefighter noise exposure during training activities and general equipment use. Journal of Occupational and Environmental Hygiene. 2013, 10, 116- 121.

9)Chung I, Chu I, Cullen M. Hearing effects from intermittent and continuous noise exposure in a study of Korean factory 
workers and firefighters. BMC Public Health. 2012, 12(87), 1-7.

10)Contrera- Moreno L, Andrade S, Motta-Castro A, Pinto A, Sala F, Stief A. Analysis of working conditions focusing on the biological risk: firefighters in Campo Grande, MS, Brazil. Work. 2012, 41, 5468- 5470.

11)Boal W, Hales T, Ross C. Blood-borne pathogens among firefighters and emergency medical technicians. Prehospital Emergency Care. 2005, 236- 246.

12)Sepkowitz K, Eisenberg L. Occupational deaths among health care workers. Emergency Infectious Diseases. 2005, 11(7), 1003- 1008.

13)Gaughan D, Siegel P, Hughes M, Chiung-Yu C, Brandon F, Corey R et al. Arterial stiffness, oxidative stress and smoke exposure in wildland firefighters. American Journal of Industrial Medicine. 2014, 57, 748- 756.

14)Hejl A, Adetona O, Diaz- Sanchez D. Inflammatory effects of wood smoke exposure among wildland firefighters working at prescribed burns at the Savannah river site, SC. Journal of Occupational and Environmental Hygiene. 2013, 10, $173-180$.

15)Adetona O, Simpson C, Onstad G, Naeher L. Exposure of wildland firefighters to carbon monoxide fine particles and levoglucosan. American Occupational Hygiene. 2013, 57(8), 979- 991.

16)Adetona $O$, Hall $D$, Naeher L. Lung function changes in world land firefighters working at prescribed burns. Inhalation Toxicology. 2011, 23 (13), 835-841.

17)Longo C, Salema A, Vieira C, Caldeira L, Oliveira Y, Almeida A. Campanha "cuidar de quem cuida de nós" ou o estudo da saúde do bombeiro Português- avaliação do impacto respiratório em corpos de primeira intervenção de combate a incêndios (resultados de 2007). Sociedade Portuguesa de Pneumologia. Congresso de Pneumologia, 5 a 7 de dezembro de 2008.

18)Dunn K, Shuman S, Stock A. Personal earborn monoxide exposures among firefighters at prescribed forest burns in the southeastern United States. Archives of Environmental and Occupational Health. 2013, 68 (1), 55- 59.

19)Greven F, Krop E, Spithoven J, Rooyackers J, Kertjens H, Heederik D. Lung function, bronquial hiperrresponsiveness and atopy among firefighters. Scandinavian Journal of Work, Environmental and Health. 2011, 37(4), 325- 331.

20)Greven F, Krop E, Spithoven J, Burger N, Rooyackers J, Kerstjens H, et al. Acute respiratory effects in firefighters. American Journal of Industrial Medicine. 2012, 55, 54- 62.

21)Ferreira A. Avaliação das alterações respiratórias induzidas por exposições ocupacionais através de metodologia não invasiva. Tese de Doutoramento em Ciências da Saúde, Especialidade de Sociologia Médica, área de Medicina Preventiva e Comunitária; Universidade de Coimbra. 2014, 1-304.

22)Nolan A, Kwon S, Cho S, Naveed B, Confort A, Prezant D et al. MMP-2 and TMP-1 predict healing of WTC-lung injury in New York city firefighters. BioMed Central- Respiratory Research. 2014, 15(5), 1-7.

23)Niles J, Webber M, Cohen $\mathrm{H}$, Hall C, Zeig-Owens R, Ye F et al. The respiratory pyramid: from symptoms to disease in World Trade Center exposed firefighters. American Journal of Industrial Medicine. 2013, 56, 870- 880.

24)Cho S, Echevaria G, Kwon S, Naveed B, Schenek E, Tsukiji E et al. One airway biomarkers of protection from upper and lower airway injury after World Trade Center exposure. Respiratory Medicine. 2014, 108, 162- 170.

25)Yang J, Jeehan D, Farioli A, Baur D, Smith D, Kales S. Sudden cardiac death among firefighters $\leq 45$ years old of age in the United States. The American Journal of Cardiology. 2013, 112, 1962- 1967.

26)Lima R. A carga de trabalho no combate aos incêndios florestais: um modelo de horário de trabalho e papel de adjunto de segurança. Tese de Mestrado em riscos e Proteção Civil, instituto Superior de Educação e Ciências. 2014, 1- 141.

27)Pukkala E, Martinsen J, Weiderpass E, Kjarheim K, Lynge E, Tryggvadottir L, et al. Cancer incidence among firefighters: 45 years of follow-up in five Nordic countries. Occupational Environmental Medicine. 2014, 71, 398- 404.

28)Daniels R, Kubale T, Yiin J, Dalm M, Hales T, Baris D, et al. Mortality and cancer incidence in a polled cohort of US firefighters from San Francisco, Chicago and Philadelphia (1950- 2009). Occupational Environmental Medicine. 2014, 71, 388- 
397.

29)Taylor N, Lewis M, Notley S, Peoples G. A fractionation of the physiological burden of the personal protective equipment worn by firefighters. European Journal of Applied Physiology. 2012, 112, 2913- 2921.

30)Carvalho C, Maia A. Perturbação pós- stress traumático e indicadores de (in)adaptação em bombeiros portugueses. Desafios de saúde e comportamento: atores, contextos e problemáticas. Atas do $1^{\circ}$ Congresso de Saúde e Comportamento dos países de língua portuguesa. Braga. 2009, 277- 290.

31)Monteiro J. Experiência de stress ocupacional em bombeiros portugueses: chorar por dentro. Mestrado em Psicologia aplicada, Especialidade de Psicologia Clínica. Instituto de Psicologia aplicada. 2008, 1-145.

32)Ferreira S. Relação entre trabalho emocional, burnout e os processos de interação na equipa de trabalho: um estudo com bombeiros sapadores portugueses. Mestrado Integrado em Psicologia; Psicologia dos Recursos Humanos, Trabalho e Organizações; Faculdade de Psicologia e Ciências da Educação; Universidade de Lisboa. 2008, 1-37.

33)Ferreira A. Personalidade e perceção do stress em bombeiros. Tese de Mestrado, Universidade Lusófona de Humanidades e Tecnologias, Faculdade de Psicologia. 2010, 1- 89.

34)Marques G. Stress e enfrentamento em uma equipa de bombeiros. Doutoramento em Ciências, Universidade de S. Paulo, Escola de Enfermagem. 2012, 1-200.

35)Carpenter G, Carpenter T, Kimbrel N, Flynn E, Pennington M, Cammarata C et al. Social support, stress and suicidal ideation in professional firefighters. American Journal of Health and Behavior. 2015, 39(2), 191- 196.

36)Jahnke S, Poston W, Haddock C, Jitnarin N. Injury among a population based sample of career firefighters in the central USA. Injury Prevention. 2013, 19, 393- 398.

37)Poplin G, Harris, R; Pollack, K et al. 2011. Beyond the fireground: injuries in the fire service. Injury Prevention, 18, $228-233$.

38)Riedel, M, Berrez S, Polisse D, Brousse E, Forget C, Marlot M et al. 24-hour of work-related injury risk of French firemen: nocturnal peak time. Chronobiology International. 2011, 28(8), 697- 705.

39)Guerra C. A importância da prevenção dos riscos sociais e profissionais nos bombeiros municipais: um estudo na zona de Santarém Ribeirinho. Tese de Mestrado em Política Social, Universidade Técnica de Lisboa. 2012, 1-80.

Fluxograma $1^{\text {a }}$ fase

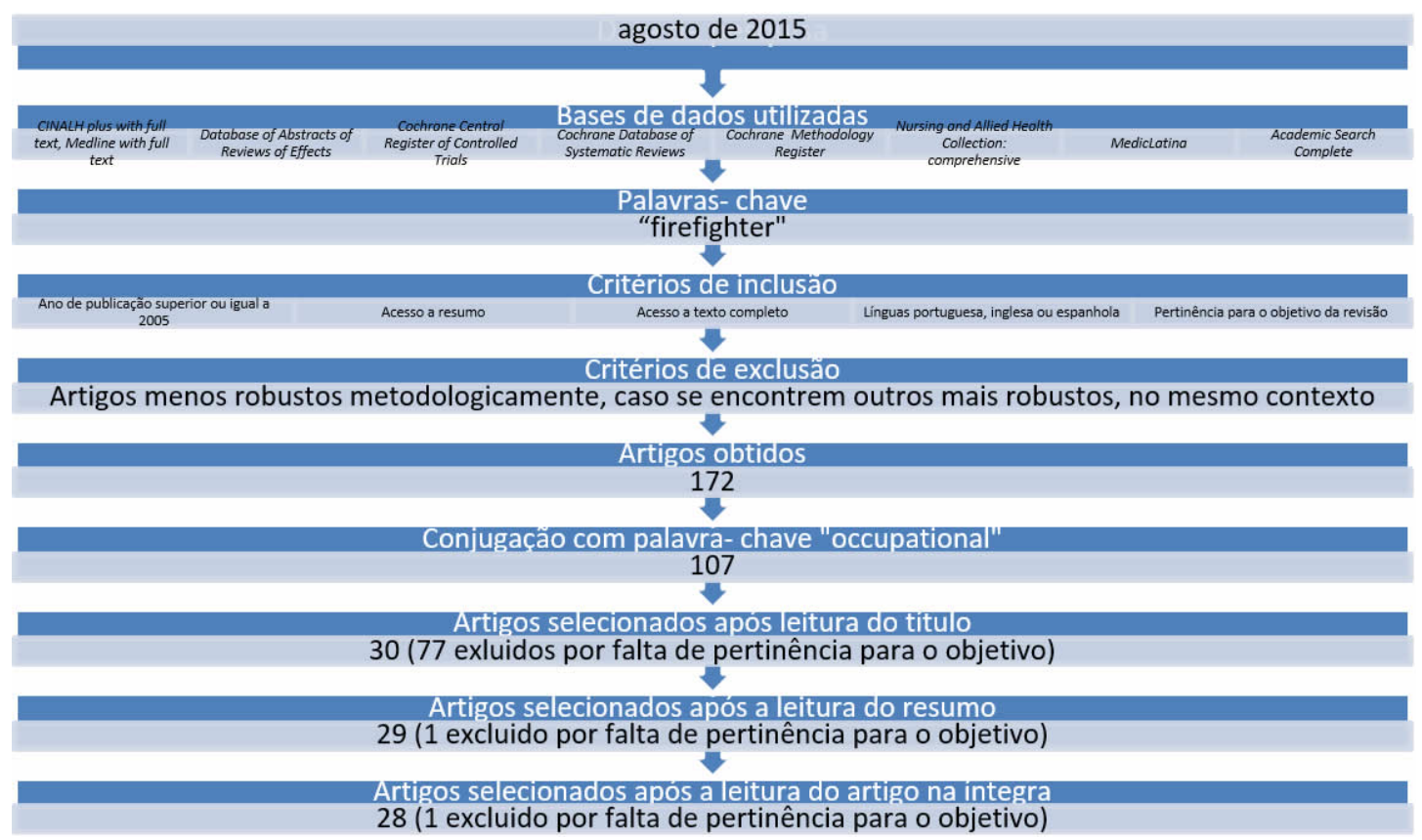




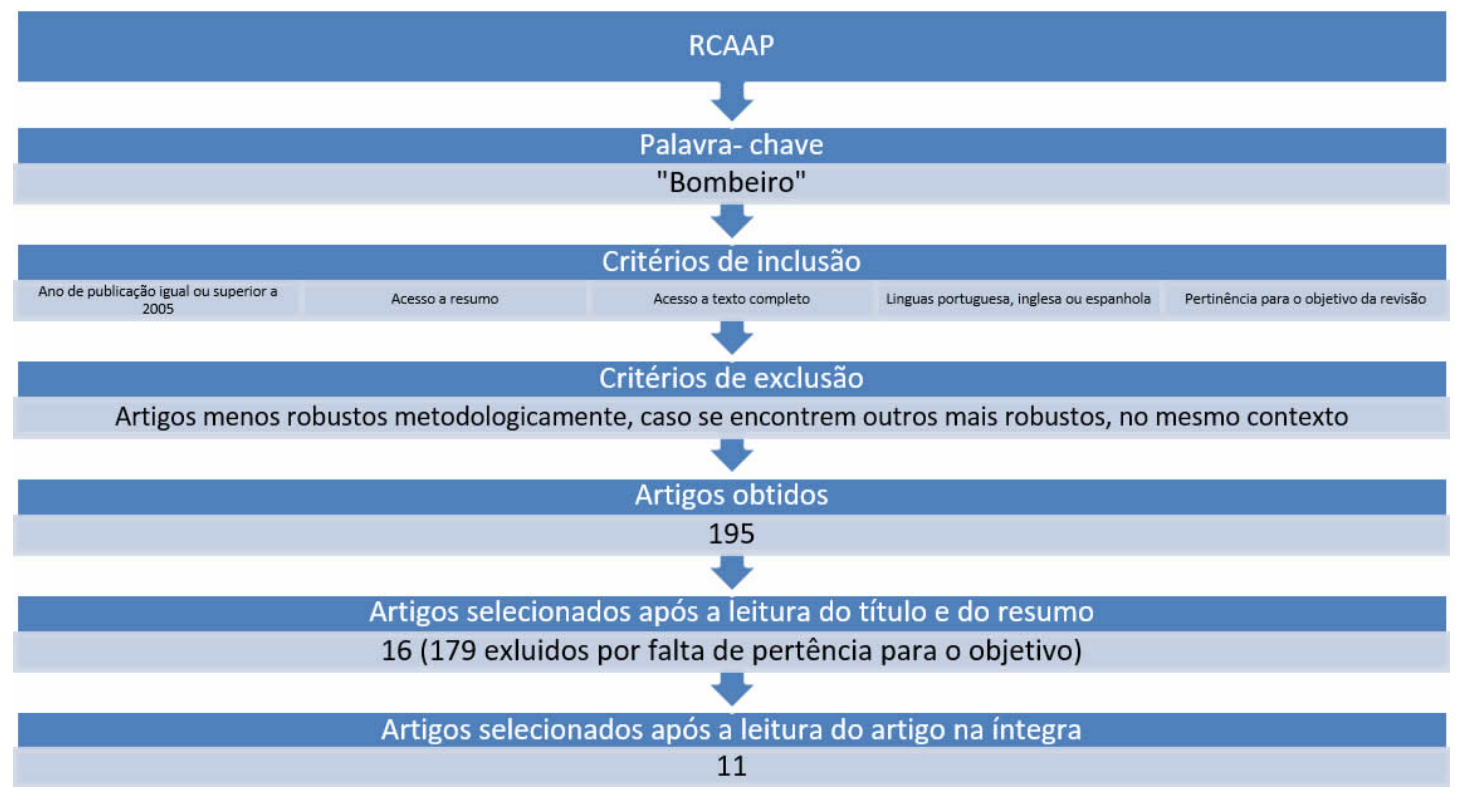

Quadro 1- Classificação metodológica dos artigos consultados

Artigo Tipo de Resumo do estudo estudo

1 Revisão bibliográfica narrativa e estudo observacional descritivo (séries de casos)

Neste estudo nacional o autor pretendeu caraterizar o stress térmico, existente no combate a incêndios, avaliando também as técnicas de arrefecimento utilizadas. Parte da informação também resultou da aplicação de um inquérito distribuído aos profissionais, para avaliar a perceção individual acerca de alguns aspetos do trabalho e conhecimentos associados. A técnica de arrefecimento ativo que demonstrou mais eficácia foi a da imersão das mãos e antebraços em água de 10 a $20^{\circ}$, com ou sem colete de arrefecimento. Na generalidade dos indivíduos avaliados, constatou-se a existência de conhecimentos reduzidos acerca destas técnicas, bem como sobre aptidão física, ambiente térmico e EPIs (aliás verificou-se a inexistência de EPIs adequados, na generalidade dos casos).

2 Ensaio clínico Nesta investigação os autores pretenderam avaliar se os bombeiros com mais tempo de serviço manifestavam evidência de adaptação ao desconforto térmico, dada a cronicidade da exposição. Foram selecionados doze bombeiros com muitos anos de serviço e doze controlos não bombeiros, ajustados pela área corporal, percentagem de gordura e aptidão cardiorrespiratória. Os autores concluíram que, apesar de as diferenças não serem significativas a nível estatístico, globalmente verificou-se a existência de uma proteção adaptativa nestes profissionais.

3 Revisão bibliográfica integrativa

Os autores pretenderam recolher informação sobre as técnicas de arrefecimento disponibilizadas para os bombeiros. Estes concluíram que a generalidade destes procedimentos não é necessária quando o ambiente em que o bombeiro repousa tem temperatura e humidade adequadas. Quando tal não ocorre poder-se-ão considerar a técnica de imergir em água o braço/ antebraço, usar peças de roupa com circulação de líquido ou de ar refrigerados (versus inserção de blocos de gelo no vestuário, dada a carga)

$4 \quad$ Ensaio clínico

Neste artigo os autores investigaram a resposta inflamatória de bombeiros com muitos anos de serviço, expostos intermitentemente a temperaturas elevadas. Foram selecionados doze profissionais e doze controlos não bombeiros, ajustando a idade, área corporal, composição corporal e pico de VO2; bem como seis bombeiros com poucos anos de serviço e seis controlos não bombeiros.

$5 \quad$ Observacional O propósito deste trabalho foi investigar quais os fatores associados ao uso de proteção auricular analítico da parte dos bombeiros. Foi selecionada uma amostra constituída por 404 profissionais, transversal provenientes de 35 corporações, em diversos estados dos EUA. Os autores concluíram que o uso destes EPIs estava estatisticamente correlacionado com a exposição ao ruído, influências interpessoais, apoio hierárquico, barreiras e perceção de suscetibilidade de surgir hipoacusia. 
Observacional

analítico

transversal

Este artigo pretendeu avaliar a existência de perda auditiva em bombeiros profissionais, em início de carreira. $O$ autor analisou audiometrias de 118 bombeiros do sexo masculino, após algum tempo de serviço e comparou-as com as realizadas no exame de admissão. Concluiu-se que existiu uma diminuição estatisticamente significativa da acuidade auditiva.

$7 \quad$ Observacional descritivo

A autora pretendeu avaliar a audição dos bombeiros, bem como quantificar acusticamente os diversos ambientes laborais envolvidos. Foram incluídos 41 profissionais. $27 \%$ destes apresentava hipoacusia, sendo que em $36 \%$ destes era de forma bilateral. A quantificação de ruido produzido pela maioria dos equipamentos utilizados ultrapassava o limiar proposto na legislação brasileira.

8 Observacional analítico transversal

Este estudo teve como objetivo avaliar a exposição ao ruído da parte dos bombeiros, durante atividades de treino e durante o uso real de alguns equipamentos de trabalho. Concluiu-se que 13 dos 15 equipamentos analisados, isoladamente, emitiam ruido igual ou superior a $85 \mathrm{dBAs}$, sendo que durante a execução das tarefas, geralmente estão vários ligados ao mesmo tempo. Para além disso, foram colocados dosímetros/ sonómetros em 93 bombeiros durante dez atividades de treino; aqui verificou-se que os profissionais estiveram expostos ao ruído, em média, nesses dias, a cerca de 70 minutos diários e o valor médio doseado foi de $78 \mathrm{dBA}$, ou seja, bem abaixo das normas aceites na generalidade dos países.

9 Observacional analítico de coorte

Esta investigação avaliou 81 trabalhadores fabris (expostos ao ruído) e 371 bombeiros, todos do sexo masculino, durante quatro anos. Os autores concluíram que ambos apresentavam perda auditiva, mas esta foi mais relevante nos trabalhadores fabris (pela continuidade da exposição durante o turno) e nos funcionários com mais de dez anos de serviço (pela cronicidade da exposição durante a vida).

10 Observacional analítico transversal

Os autores desta investigação pretenderam analisar o risco biológico existente entre bombeiros, nas suas atividades de transporte de doentes e apoio a nível de socorrismo em caso de acidentes, numa cidade brasileira. A amostra selecionada foi constituída por 307 profissionais; destes, $63,5 \%$ já tinham experimentado algum acidente laboral associado ao contato inapropriado com sangue ou outros fluidos corporais relevantes. Tal demonstrou ter correlação estatisticamente significativa com o não uso adequado dos EPIs. Os autores destacaram também que se estima que $57,1 \%$ de todos os pacientes apresentavam risco de contato com fluidos corporais passíveis de causar alguma infeção, o que correspondeu a cerca de $16 \%$ do tempo laboral total.

11 Revisão bibliográfica narrativa

Neste artigo os autores efetuaram uma revisão bibliográfica narrativa acerca do risco biológico existente para bombeiros e outros técnicos de emergência, com destaque para os agentes transmissíveis através do sangue. Ainda assim é mencionado que, em função dos estudos consultados, estes profissionais não apresentaram prevalência superior de hepatite $C$, por exemplo, em relação à população geral.

12 Observacional descritivo

Esta investigação teve como objetivo estimar o risco de mortalidade laboral entre profissionais de saúde (englobaram os profissionais que fazem assistência e transporte de doentes), tal como está calculado para outros setores ocupacionais. Os autores concluíram que existiu um risco entre 17 e 57 por milhão de trabalhadores, usando dados dos EUA.

13 Observacional analítico transversal

Os autores pretenderam avaliar a associação existente entre o stress oxidativo, função cardiorrespiratória e alguns sintomas, perante a exposição ocupacional proveniente do fumo de incêndios florestais. Para atingir tais objetivos, foram utilizados dois questionários, bem como métodos para a avaliação da rigidez arterial, espirometria e doseamento urinário da 8-isoprostano, 8-OHdG e do levoglucosano. Concluiu-se que os biomarcadores de stress oxidativo podem servir como indicadores da presença de rigidez arterial, em bombeiros florestais.

14 Observacional analítico de caso-controlo

Uma vez que os bombeiros florestais estão expostos a grandes quantidades de fumo e este está associado a indução de processos inflamatórios, os autores idealizaram avaliar alguns marcadores inflamatórios nestes profissionais, como a IL-1 $\beta$, IL-8, proteína $C$ reativa, SAA, ICAM1 e Vcam-1. A amostra englobou doze indivíduos a trabalhar numa reserva florestal (avaliados antes e depois do turno) e 24 controlos. Os autores concluíram que se verificou um aumento da IL-8 nos bombeiros florestais, após o turno.

15 Observacional analítico transversal

Nesta investigação os autores, usando uma amostra de 18 bombeiros, avaliaram a exposição a matéria particulada, com dimensão média de $2,5 \mu$, bem como levoglucosano e monóxido de carbono, durante 30 incêndios ocorridos numa reserva ecológica. O nível de exposição obtido para a primeira e terceira situações foi equivalente ao já descrito na bibliografia mas inferior em relação ao segundo. 
Observacional analítico de coorte
A bibliografia descreve que há um declínio na função pulmonar dos bombeiros florestais, à medida que o turno decorre; contudo, segundo os autores deste trabalho, tais investigações nunca se restringiram apenas aos dias de trabalho, pelo que tal decréscimo poderia apenas espelhar a evolução circadiana da função pulmonar. Para avaliar tal foi quantificada a capacidade vital forçada, volume expiratório forçado no primeiro segundo e o fluxo expiratório forçado entre 25 e $75 \%$, bem como o pico de fluxo expiratório de bombeiros florestais, antes e após o turno, no total de 989 medições efetuadas, ao longo de 22 dias de incêndio e 43 dias sem incêndios. Os autores verificaram que não existiam diferenças estatisticamente significativas ao longo do turno, nos dias de incêndio, mas existiu um declínio significativo ao longo dos dias de incêndio, pela eventual exposição cumulativa.
17 Observacional analítico transversal

Observacional analítico de coorte
Os autores desta investigação tentaram monitorizar a saúde dos bombeiros portugueses, destacando a exposição a fumos com diversos agentes químicos e a avaliação espirométrica. Foram estudados 357 profissionais, provenientes de 44 corporações.
Os autores deste trabalho avaliaram a exposição ao monóxido de carbono entre bombeiros florestais do sudoeste dos EUA. Foi utilizado um questionário para recolher dados relativos a tarefas laborais e exposição ao fumo. A amostra foi constituída por 20 indivíduos, seguidos durante duas épocas de incêndio. Os autores verificaram que existia uma boa correlação entre a exposição ao monóxido de carbono e a autoperceção de exposição ao fumo, mas não com a quantidade total de terreno ardido, por exemplo.
19 Observacional analítico transversal
Este estudo pretendeu avaliar eventuais associações entre a função pulmonar, hiperresponsividade brônquica e atopia, entre bombeiros expostos ao fumo. A amostra englobou 401 profissionais holandeses, escolhida de forma aleatória, entre os indivíduos já estudados; foram realizados espirometria, teste de provocação com metacolina e análises sanguíneas (em função da atopia); a exposição ao fumo foi avaliada através de um questionário. Os autores concluíram que a exposição ao fumo estava associada ao número de incêndios no último ano, sobretudo nos atópicos, mesmo com o ajustamento dado pelo eventual enviesamento proporcionado pelo tabagismo, sexo, atopia, idade e exposição laboral a outros riscos relevantes. Contudo, os EPIs a nível respiratório não eram utilizados adequadamente.
20 Observacional analítico transversal
Os autores deste trabalho pretenderam avaliar eventuais associações entre a infeção respiratória aguda, hiperresponsividade brônquica, níveis séricos de pneumoproteinas e a exposição ao fumo. A amostra englobou 51 profissionais. As colheitas sanguíneas foram realizadas $24 \mathrm{~h}$, uma semana e três meses após a exposição, no sentido de verificar alterações na IgE associada aos ácaros, pelo de animais e pólenes; a expetoração foi avaliada cinco dias após a exposição e a espirometria e o teste de provocação com metacolina foram realizados uma semana após a exposição; sendo que esta última foi avaliada através de um questionário. Os autores não encontraram diferenças na hiperresponsividade brônquica e nos níveis séricos de pneumoproteinas; contudo, o número de neutrófilos na expetoração foi elevado, bem como da IL-8 (mesmo aos três meses). Os autores concluíram então que a exposição ao fumo induz inflamação sistémica a longo prazo, mesmo na ausência de hiperresponsividade brônquica.
Observacional analítico de coorte
O autor pretendeu investigar qual o papel que algumas metodologias não invasivas (como os biomarcadores do condensado respiratório e a fração exalada de óxido nítrico) poderão ter para a Saúde Ocupacional. Para atingir tal objetivo, foi avaliada uma amostra de bombeiros durantes três anos, expostos aos fumos provenientes dos incêndios florestais. Globalmente, verificou-se uma diminuição significativa em alguns parâmetros espirométricos (como o FEV1, DEM50, DEM25 e DEM25-75). Foram também analisados e comparados os dados obtidos em trabalhadores da indústria do plástico. $O$ autor concluiu que as técnicas de avaliação mais clássica poderão ser auxiliadas por estes métodos mais recentes.
Observacional analítico de caso-controlo
Após o evento ocorrido a 11 de setembro de 2001, entre os bombeiros de Nova lorque, alguns apresentaram diminuição da função pulmonar, sendo que em parte destes a situação revertia. Os autores quantificaram o valor expiratório forçado no primeiro segundo em 2002 e 2008; a nível sérico foram avaliadas as metaloproteínas e respetivos inibidores teciduais, em casos e controlos. Os autores concluíram que $99 \%$ da amostra estudada conseguiu normalizar as alterações respiratórias encontradas inicialmente. A amostra foi constituída por 801 indivíduos, na qual não existiam indivíduos com alterações espirométricas antes do evento, nem tabagistas. 
Observacional analítico de coorte
Este artigo pretendeu utilizar um modelo explicativo relativo à associação existente entre os sintomas e as alterações pulmonares (como asma, bronquite, enfizema) nos bombeiros expostos ao evento de 11 de setembro de 2001. As avaliações foram efetuadas quatro e nove anos depois. A amostra foi constituída por 6931 profissionais expostos. Quatro anos depois, $58 \%$ dos indivíduos não apresentava sintomas ou fazia terapêutica; $23 \%$ apresentavam alguma semiologia, ainda que sem diagnóstico concreto; $15 \%$ apresentava um diagnóstico concreto (com destaque para a asma) e $4 \%$ apresentava mais que um diagnóstico (asma, bronquite e/ou enfizema).

24 Observacional analítico de coorte

Alguns autores verificaram que os bombeiros expostos ao evento de 11 de setembro de 2001 apresentavam rinossinuvite crónica e alterações no volume expiratório forçado no primeiro segundo. Este trabalho pretendeu avaliar a eventual associação entre este diagnóstico e alguns parâmetros da resposta imune. A amostra inata pode proporcionar alguma proteção para a função pulmonar, após este tipo de exposição.

25 Observacional analítico de caso-controlo

A morte súbita cardíaca é uma das principais causas de morte em bombeiros nos EUA; contudo, na generalidade dos casos existe doença coronária prévia e idade mais avançada. Os autores pretenderam avaliar esta ocorrência pelos diversos grupos etários, nesta profissão. Foi dado particular destaque para a existência de obesidade, doença coronária, cardiomegalia, HTA, hipertrofia ventricular esquerda e tabagismo. Os autores concluíram que a morte súbita em bombeiros mais jovens estava associada a opções de estilo de vida preveníveis.

Observacional descritivo, séries de casos

O autor pretendeu avaliar a segurança laboral dos bombeiros do distrito de Viana do Castelo, com destaque para a gestão do tempo dos operacionais nos turnos efetuados; ou seja, o objetivo direto era investigar se existia correlação entre o elevado número de ocorrências/ acidentes e o tempo de trabalho executado, sobretudo na altura do verão e dos incêndios florestais associados. $\mathrm{O}$ autor concluiu que não existe um controlo rigoroso do tempo de trabalho, sendo que, por vezes, os turnos ultrapassam as $\mathbf{5 0}$ horas consecutivas. Os dados foram obtidos através de um questionário elaborado pelo autor, após revisão bibliográfica narrativa.

27 Observacional analítico de coorte

Uma vez que os bombeiros estão expostos a várias condições eventualmente carcinogénicas, os autores pretenderam comparar a incidência de patologia oncológica destes profissionais nos países nórdicos, com a população geral. Para tal usaram a população registada na Finlândia, Noruega, Suécia, Dinamarca e Islândia e os cancros diagnosticados entre 1961 e 2005 . A amostra incluiu 16422 bombeiros do sexo masculino. Os autores verificam um excesso de risco moderado para a patologia oncológica em geral, com destaque para a próstata e melanoma (entre os 30 e os 49 anos); por sua vez, para mais que 75 anos, verificou-se uma incidência aumentada para mieloma múltiplo, adenocarcinoma pulmonar e mesotelioma. Ao contrário de outros estudos prévios, não se encontrou aumento de risco para o cancro testicular. Considera-se que a etiologia deste aumento global de risco possa estar associada à exposição a hidrocarbonetos aromáticos policíclicos, asbestos e turnos noturnos e/ ou rotativos (pela cronodisrrupção).

28 Observacional analítico de coorte

Este estudo pretendeu avaliar a mortalidade e incidência de patologia oncológica existente em bombeiros, entre 1950 e 2009, nos EUA. A amostra incluiu 29993 profissionais. Globalmente os autores concluíram que existiu um aumento moderado de risco em alguns tipos de cancro (com destaque para a parte digestiva e respiratória- incluindo mesoteliomas, eventualmente devido aos asbestos), mas não aos níveis hematológico ou linfático.

29 Observacional analítico transversal

A carga transportada pelo bombeiro diminui a capacidade física de trabalho e aumenta o risco de lesão, sendo que parte desta carga é constituída pelos próprios EPIs. A amostra estudada foi constituída por doze bombeiros e doze bombeiras para a prova de obstáculos; dez mais dez para a prova do tapete rolante e dez mais dez, respetivamente, para a prova da caminhada e salto entre bancos, com e sem EPIs (roupa, capacete, aparelho de proteção respiratória e botas), no total de 43 profissionais. Verificou-se que o uso destes acessórios diminui a tolerância ao exercício em $56 \%$ e a performance em $27 \%$. Individualmente, o EPI com mais impacto foram as botas. Os autores concluíram que a forma mais eficiente de reduzir o esforço seria diminuir o peso do calçado e melhorar o conforto térmico da farda.

30 Observacional analítico transversal
A exposição continuada a situações adversas pode originar problemas a nível de saúde mental; contudo, poderão existir eventos/ condições protetores. Este estudo teve como principais objetivos analisar a prevalência de exposição a alguns eventos adversos em bombeiros a exercer no norte de Portugal, destacando a semiologia eventualmente associada à perturbação pós-stress traumático. A amostra foi constituída por 296 indivíduos e a informação foi colhida através de um questionário. Os autores concluíram que $12 \%$ apresentava sintomas de perturbação pós-stress traumática, sendo os seus preditores a gravidade da exposição e a menor capacidade de coping. 
Fenomenologia Nesta tese de mestrado a autora pretendeu investigar como é que os bombeiros portugueses definem stress laboral, como o vivenciam, quais as etiologias atribuídas, bem como eventuais diferenças em função do género. A amostra foi constituída por sete bombeiros profissionais e foi utilizado um método qualitativo (análise fenomenológica e interpretativa), tendo-se também usado entrevistas semiestruturadas. A autora realçou que seria pertinente dar formação a estes profissionais, relativa à gestão de conflitos, treino de competências, bem como técnicas para lidar com a ansiedade, depressão e sentimentos de inadequação.

32 Observacional

Nesta tese de mestrado pretendeu-se analisar a eventual relação entre o trabalho emocional, analítico transversal burnout e a interação na equipa de trabalho. A amostra incluiu 417 bombeiros portugueses de seis corporações (Setúbal, Lisboa, Coimbra, Porto, Gaia e Braga), aos quais foi aplicado um questionário. Os autores concluíram que, apesar de o burnout não ser frequente, a dissonância emocional pode ser encarada como uma eventual exigência laboral.

33 Observacional analítico

Esta tese de mestrado pretendeu avaliar as eventuais correlações existentes entre traços de transversal personalidade e a perceção de stress em bombeiros. A amostra foi constituída por 302 bombeiros pertencentes a corporações do Ribatejo e Extremadura (sendo que 238 eram do sexo masculino), entre os 17 e os 73 anos (média de 33 anos). $O$ autor encontrou associações entre neuroticismo e stress (relação positiva) e entre extroversão e conscienciosidade (relação inversa). O autor também verificou que os bombeiros profissionais apresentam um nível mais intenso de stress, versus os voluntários; tal como os bombeiros com menos de nove anos de serviço. Entre géneros, o feminino apresentou níveis de stress mais elevados.

34 Observacional analítico transversal

Nesta tese de doutoramento a autora realça que, dados os riscos laborais existentes nos bombeiros, poderá surgir burnout. Este trabalho teve como objetivo avaliar a autoperceção de stress laboral, existência de hardiness e estratégias usadas. A amostra foi constituída por 132 indivíduos de uma cidade do estado de S. Paulo. Os autores concluíram que os trabalhadores apresentavam níveis moderados de stress laboral, ainda que sem situações de burnout.

35 Observacional analítico transversal

Neste trabalho os autores pretendiam avaliar a eventual proteção que o suporte social poderá proporcionar em relação a ideias suicidas neste setor profissional. A amostra foi constituída por 334 bombeiros. Os autores concluíram que com níveis elevados de apoio social não se encontrou associação entre o stress ocupacional e as ideias suicidas; contudo, tal verificou-se nos casos de suporte social mais frágil.

36 Observacional

A incidência de traumatismo entre os bombeiros é elevada, devido à exigência física de algumas analítico transversal tarefas; contudo, não é geralmente avaliada a eventual associação entre estas ocorrências e algumas caraterísticas/ riscos individuais. A amostra foi constituída por 462 bombeiros de onze corporações da região do vale do Missouri; escolhidas aleatoriamente. Foram analisadas eventuais relações entre os traumatismos, caraterísticas demográficas, composição corporal, aptidão cardiovascular e comportamentos de estilo de vida. Os autores concluíram que a prática de exercício durante os treinos como bombeiros traz benefícios, ainda que possam ocorrer mais lesões durante os mesmos.

37 Observacional descritivo

Apesar de serem frequentes os acidentes entre bombeiros, poucos estudos identificaram a etiologia dos mesmos, segundo estes autores. Os dados foram colhidos numa corporação de bombeiros, entre 2004 e 2009. A incidência anual obtida foi de $17,7 \%$ acidentes por 100 funcionários; cerca de um terço esteve associado aos treinos físicos, transporte de pacientes e tarefas no combate a incêndios. As lesões mais frequentes foram os entorses, contusões e lacerações; 95,6\% das lesões detinham gravidade; apesar que as lesões eram mais graves no combate a incêndios, as que exigiam mais tempo de ausência ao trabalho eram as que estavam associadas ao transporte de doentes.

38 Observacional analítico de coorte

Este trabalho pretendeu analisar a eventual evolução circadiana da ocorrência de acidentes de trabalho em bombeiros franceses de 2004 a 2007. Os autores concluíram que os acidentes são mais frequentes de madrugada, aliás até estimaram que o risco era aqui duas vezes superior ao existente durante a tarde.

39 Pesquisa documental, estudo de caso Nesta tese de mestrado o autor pretendeu analisar globalmente vários parâmetros associados à e revisão bibliográfica narrativa 
(1) Santos M.: Licenciada em Medicina; Especialista em Medicina Geral e Familiar; Mestre em Ciências do Desporto; Especialista em Medicina do Trabalho; Presentemente a exercer nas empresas Medicisforma, Clinae, Servinecra e Serviço Intermédico; Diretora Clínica da empresa Quercia; Diretora da Revista Portuguesa de Saúde Ocupacional on line

(2) Almeida A:. Mestre em Enfermagem Avançada; Especialista em Enfermagem Comunitária; Pós-graduado em Supervisão Clínica e em Sistemas de Informação em Enfermagem; Docente na Escola de Enfermagem (Porto), Instituto da Ciências da Saúde da Universidade Católica Portuguesa; Diretor Adjunto da Revista Portuguesa de Saúde Ocupacional on line

Santos M, Almeida A. Principais riscos e fatores de risco ocupacionais associados aos bombeiros, eventuais doenças profissionais e medidas de proteção recomendadas. Revista Portuguesa de Saúde Ocupacional on line. 2016, volume 1, 1-15. 